\title{
TRANSACTION BASED RISK ANALYSIS - USING COGNITIVE FUZZY TECHNIQUES
}

\author{
ELME SMITH ${ }^{1}$, JAN H.P. ELOFF ${ }^{2}$ \\ smithe@unisa.ac.za.
}

University of South Africa, Department of Computer Science and Information Systems, PO Box 392, PRETORIA 0003, Republic of South Africa

Tel: (+2712) 429-6309

Fax: (+2712) 429-6848

eloff@rkw.rau.ac.za.

Rand Afrikaans University, Department of Computer Science, PO Box 524, AUCKLAND PARK 2006, Republic of South Africa

Tel: (+271I) 489-2842

Fax: (+2711) 489-2138

Keywords: cognitive fuzzy-logic approach; fuzzy cognitive map; information security; risk analysis; risk assessment; risk-management methodology; transactions

Abstract: This paper is devoted to the presentation of a risk-management methodology specifically developed for assessing and analysing risks incurred by the business transactions of an organisation. A transaction is a part of a business information system that has one or other functional goal. An order-entry-anddelivering-of-goods transaction forming part of an MRP (materials, requirement \& planning) information system is discussed as an example. The proposed methodology includes five successive stages in all, namely initiation, domain analysis, risk assessment, risk analysis and domain monitoring. This paper focuses on the risk analysis stage.

The methodology enhances risk management in that it incorporates cognitive fuzzy-logic techniques - as opposed to quantitative techniques such as annual loss exposure (ALE) calculation - to assess and analyse the risks. In this way, it is ensured that full cognisance is taken of the intuitive nature of human observation when assessing and analysing the possible risks to be incurred in an organisation. In addition, the methodology takes into account the vagueness of the decision making process with respect to securing transaction information. 


\section{INTRODUCTION}

Information technology is currently being employed in business environments across the globe, resulting in significant improvements in the efficiency and quality of all services rendered. The occurrence of a risk, such as the exposure of highly confidential and sensitive transaction data to outsiders, could compromise not only the customer's privacy, but also quite literally the well-being of the organisation. It is, imperative, therefore, to be able to identify possible risks in good time and to implement the necessary security controls in order to protect the business as a whole.

Broadly speaking, risk management can be defined as that process by means of which security controls are identified and implemented that will, at best, prevent risks fiom occurring and, at worst, minimise their effect if they were to occur [1-3]. In currently available risk-management techniques the emphasis has, however, mainly been placed on the input and manipulation of numbers. Human common sense and intuition, which form the basis of any risk-management exercise, are most of the time neglected. These techniques, furthermore, address risk analysis fiom an information- and resources-asset point of view. They require organisations to identify all assets, followed by the identification of the applicable risks. Risks identified in such a way are not modelled fiom a business point of view. Management might be interested to know what risks are involved during the execution of a specific type of business transaction. It is, therefore, essential to protect the transaction as a basic business unit.

The principal aim of this paper is, therefore, not to discourage the use of powerful risk-management techniques (such as CRAMM), but rather to propose a new way of handling risk management in an integrated business environment. The methodology incorporates both the vague and intuitive aspects of the normal business environment by following a cognitive fuzzylogic approach to the assessment and analysis of risks that might be incurred in this environment. The methodology is aimed at identifjmg the high-risk areas within a typical business environment. The methodology also helps to manage risks by facilitating the decision-making process with respect to securing information assets.

The proposed methodology includes five successive stages in all, namely initiation, domain analysis, risk assessment, risk analysis and domain monitoring. The first section of the paper will be devoted to a synoptic and high-level overview of the proposed methodology, followed by an in-depth discussion on the risk analysis stage. 


\section{A HIGH-LEVEL OVERVIEW OF THE PROPOSED RISK-MANAGEMENT METHODOLOGY}

The proposed risk-management methodology enhances risk management by considering the route that a business transaction follows within an organisation. Normally different sections within the organisation execute different tasks on the route that a transaction follows. Consider, for example, an order-entry-and-delivering-of-goods transaction in a retail environment. Such a transaction route can include different departments (sections) of the organisation, where each is responsible for a different task. Tasks forming part of such a transaction may include order entry, checking availability of stock, picking the stock and despatch the goods to the delivery address. A route that a transaction follows will further on be referred to as a transaction information route.

Transaction information routes indicate and identify all management processes and IT components that are required for the successful execution of a transaction. A transaction information route is used to assess and analyse the risks from an information security perspective. The advantage of performing risk analysis in this way is that composite risks from a business point of view can be calculated.

\section{STAGE 1:}

Iritiction

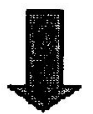

STAGE 2:

Domain and ysis

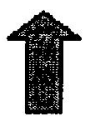

STAGE 5:

Domain monitoring

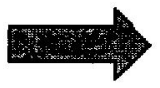

RISK MANAGEMENT

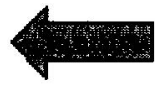

STAGE 3:

Risk essessnent

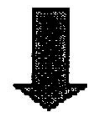

STAGE 4:

Risk gnalysis

Figure 1. A graphic representation of the various stages in the proposed risk-management methodology 
Information-technology risk management can be defined in terms of the proposed methodology as starting with an initiation stage (see figure 1). The methodology further includes four successive iterative stages, namely domain analysis, risk assessment, risk analysis and domain monitoring.

During the first stage (viz. initiation), the scope of the required riskmanagement project needs to be determined. The scope will on a high level identify the business transactions, also referred to as transaction information routes, that are ofmost importance to the organisation.

The identified transaction information routes will be analysed and disseminated in the second stage (viz. domain analysis). All the business sections participating during the execution of a transaction, identified during the previous phase, must be identified. A transaction information route comprises a fixed number of participating sections. A typical order-entryand-delivery-of-goods transaction can, for example, include participation of the following business sections: order entry, checking availability of stock, picking the stock and despatching of goods.

Transaction information routes are further sub-divided into phases. A phase on a transaction information route represents the work done by a specific section. The technologies employed to store and process information during each phase of a transaction is vulnerable to risks. Different technologies (such as database files, paper files, microfilm and a LAN server) can be employed by each section during the execution of a transaction to store and process information. The model proposed in this paper promotes, or enforces, the different sections within an organisation to take responsibility for ownership of information assets. It is, therefore, essential that security controls be implemented in each phase at best to prevent or at least to minimise the risks that may possibly be incurred. The security controls already implemented must also be identified.

Figure 2 depicts a typical transaction information route for an orderentry-and-delivering-of-goods transaction in a retail environment.

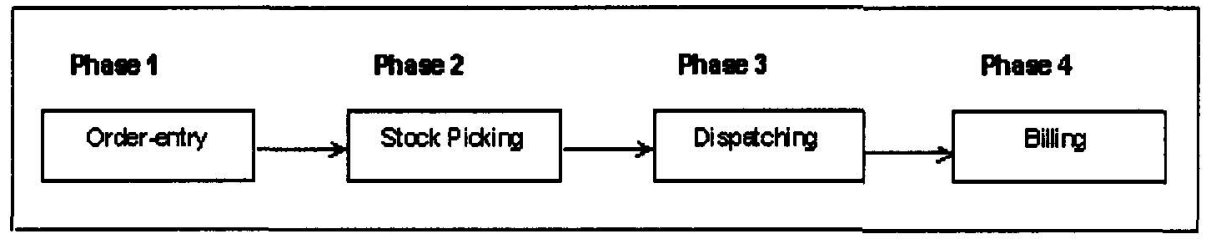

Figure 2. Route followed by an order-entry-and-delivering-of-goods transaction in a retail environment 
The technologies and management processes employed in each phase to store and process transaction based information and the security controls implemented are not fixed, in the sense that the technologies and procedures can be upgraded and new security controls might be implemented over time. These technologies and procedures do not, however, exist in isolation. They interact and, in this way, exert a distinct influence on the possibility of risks incurring in an organisation. The more access capabilities and privileges defined for a transaction in a certain phase along a transaction information route, the greater the likelihood, for example, of the transaction's information being exposed to unauthorised parties. The risk management methodology proposed in this paper, therefore, considers not only the technologies and procedures that interact, but also their relationships with each other and their effect on the likelihood of IT risks being incurred.

The principal aim of the third stage (viz. risk-assessment) is to determine a risk value for each phase in a transaction information route. This risk value is based on the information-technology domain, including technology and management processes, of a transaction's information route. A cognitive fuzzy-modelling approach is followed to calculate risk values for each phase of a transaction information route. This approach ensures that full cognisance be taken of human common sense and intuition during the assessment and analysis of risks. As a detailed explanation of the cognitive fuzzy-modelling approach, for the risk assessment phase, falls outside the scope of this paper, the reader is referred to [4] for more information on this approach.

During the fourth stage (viz. risk analysis) decisions are made regarding the risk values calculated in the previous stage (that is, the risk-assessment stage). The risk-analysis stage is aimed at identifying high-risk transaction information routes (that is, critical transaction information routes) in a typical business environment with a view to enhancing the information security of such organization. The argumentation is that if management addresses the security problems exerted by the critical transaction information routes, the security issues in the less critical routes will also be addressed. This stage will be discussed in more detail in paragraph 3.

Finally, the organisation must be monitored during the fifth stage (viz. domain monitoring) in order to pinpoint any changes in its dynamic nature, including new risks that might occur. The latter stage, however, constitutes an ongoing process through which further or new risks could be identified that might even require a partial or complete iteration of the current riskmanagement methodology. 


\section{STAGE 4: FUSKANALYSIS}

The activities to be performed during the risk-analysis stage are depicted in figure 3 .

\subsection{Determine, which risk values, associated with each phase along a transaction information route give cause for concern. List the critical phases along each transaction information route (Stage 4 task 4.1)}

During the risk-analysis stage, decisions are made regarding the risk values calculated for each phase along a specific transaction information route during the previous stage (that is, the risk-assessment stage). A phase could be classified as a "low-risk" phase if its risk value were to fall between 0 and 350, as a "medium-risk" phase if its risk value were to fall between 351 and 650 or as a "high-risk" phase, if its risk value were to fall between 651 and 1000 . The latter classification is based on a numeric scale ranging from 0 to 1000 , with 1000 representing the highest possible risk value. The phases classified as "high-risk" phases give cause for concern.

The risk-analysis stage is aimed at identifjmg high-risk transaction information routes (that is, critical transaction information routes) in an organization with a view to dancing the information security of such organization. 


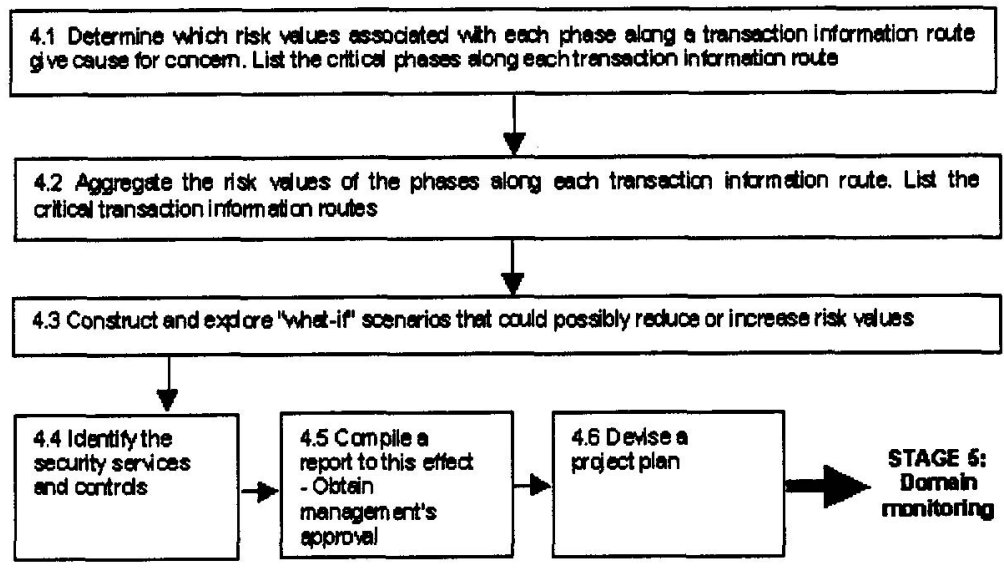

Figure 3. Stage 4: Risk Analysis

\subsection{Aggregate the risk values of the phases along each transaction information route. List the critical transaction information routes (Stage 4 task 4.2)}

The present methodology proposes a set of heuristics, summarised in table 1, for aggregating the risk values for all the phases along a specific transaction information route.

Table 1. Heuristics for aggregating risk values of a phase

\begin{tabular}{|c|c|}
\hline Condition & Risk value of transaction route (RROUTE) \\
\hline $\begin{array}{l}\text { Number of critical phases } \\
\text { along transaction } \\
\text { information route }\end{array}$ & $\mathrm{R}_{\text {ROUTE }}=\sum_{\mathrm{i}=1}^{\mathrm{m}} \mathrm{R}_{\mathrm{i}} / \mathrm{m}$, where \\
\hline$>50 \%$ & $\begin{array}{l}\mathrm{m} \text { is the number of critical phases along the transaction } \\
\text { information route and } \\
\mathrm{R}_{\mathrm{i}} \text { is the risk value of the ith critical phase along the transaction } \\
\text { information route. }\end{array}$ \\
\hline \multirow[t]{4}{*}{$\begin{array}{l}\text { Number of critical phases } \\
\text { along transaction } \\
\text { information route }<50 \%\end{array}$} & $\mathrm{R}_{\text {ROUTE }}=\left[\sum_{\mathrm{i}=1}^{\mathrm{m}} \mathrm{R}_{\mathrm{i}}+\sum_{\mathrm{j}=1}^{\mathrm{n}} \mathrm{R}_{\mathrm{j}}\right] / \mathrm{p}$, where \\
\hline & $\begin{array}{l}\mathrm{p} \text { is the number of phases along the transaction information } \\
\text { route }\end{array}$ \\
\hline & $\begin{array}{l}R_{i} \text { is the risk value of the } i^{\text {th }} \text { critical phase along the } \\
\text { transaction information route }\end{array}$ \\
\hline & $\begin{array}{l}\mathrm{R}_{\mathrm{j}} \text { is the risk value of the } \mathrm{j}^{\text {th }} \text { non-critical phase along the } \\
\text { transaction information route. }\end{array}$ \\
\hline
\end{tabular}


Number of critical phases along transaction information route $>50 \%$
$\mathrm{R}_{\text {ROUTE }}=\sum_{\mathrm{i}=1}^{\mathrm{m}} \mathrm{R}_{\mathrm{i}} / \mathrm{m}$, where

$\mathrm{m}$ is the number of critical phases along the transaction information route and

$\mathrm{R}_{\mathrm{i}}$ is the risk value of the $\mathrm{i}^{\text {th }}$ critical phase along the transaction information route.

The aim of aggregating the risk values of all the phases along a specific transaction information route is to obtain an overall risk value for that transaction information route. Such risk value could then form the basis for identifying critical transaction information routes in the organisation. The classification of a transaction information route as a "high-risk", "mediumrisk" or "low-risk" route is done in the same manner as that of the phases.

The complete set of transaction information routes in the organisation are analysed in a similar way. In this way, the high-risk areas in the organisation can be pinpointed. This will, in turn, present management with a clear picture of the specific transaction information routes to be followed in the organisation that need to be investigated when deciding on the implementation of security controls with a view to enhancing the information security of the organisation in question.

\subsection{Construct and explore "what-if" scenarios that could possibly reduce or increase risk values (Stage 4 task 4.3)}

The security related issues that play a vital role in the execution of the critical phases need to be identified and investigated. Examples of security related issues are the number of employees that are allowed access to the transaction information and the level of access rights allocated. The proposed methodology requires that the relationships between the various issues be established as they do not act in isolation, but interact with and influence each other. This will be discussed in more detail later on.

Security related issues occurring in an organisation are not easily quantified. Ideally, therefore, one wants a representation mechanism that can be used in a cognitive and intuitive manner to represent the relationships between these issues. A graph structure, called a "Fuzzy Cognitive Map" (an "FCM"), is one example of such mechanism [5, 6, $7 \& 8$ ]. FCMs are fuzzy-graph structures that provide an expressive and flexible method of capturing and representing complex relationships in an intuitive manner, In 
case of an intuitive activity such as risk management, the FCM naturally represents the "human" way of thinking.

The risk management methodology presented in this paper employs FCM's to represent the relationships between the various security related issues to be effected in a specific phase in a cognitive and intuitive way. An FCM consists of nodes, which, in turn, represent the issues that may occur to some degree, and edges that describe the relationships (causal flow) between these issues. One of the activities that form part of the risk-analysis stage is determining the strengths of these relationships. The relationships have "fuzzy" strengths in the interval range [-1,1]. The strength of a relationship indicates the degree to which one issue affects another. These strengths are determined intuitively. We need to determine the strengths of all relationships depicted by the edges in the FCM. Consider figure 4 below:

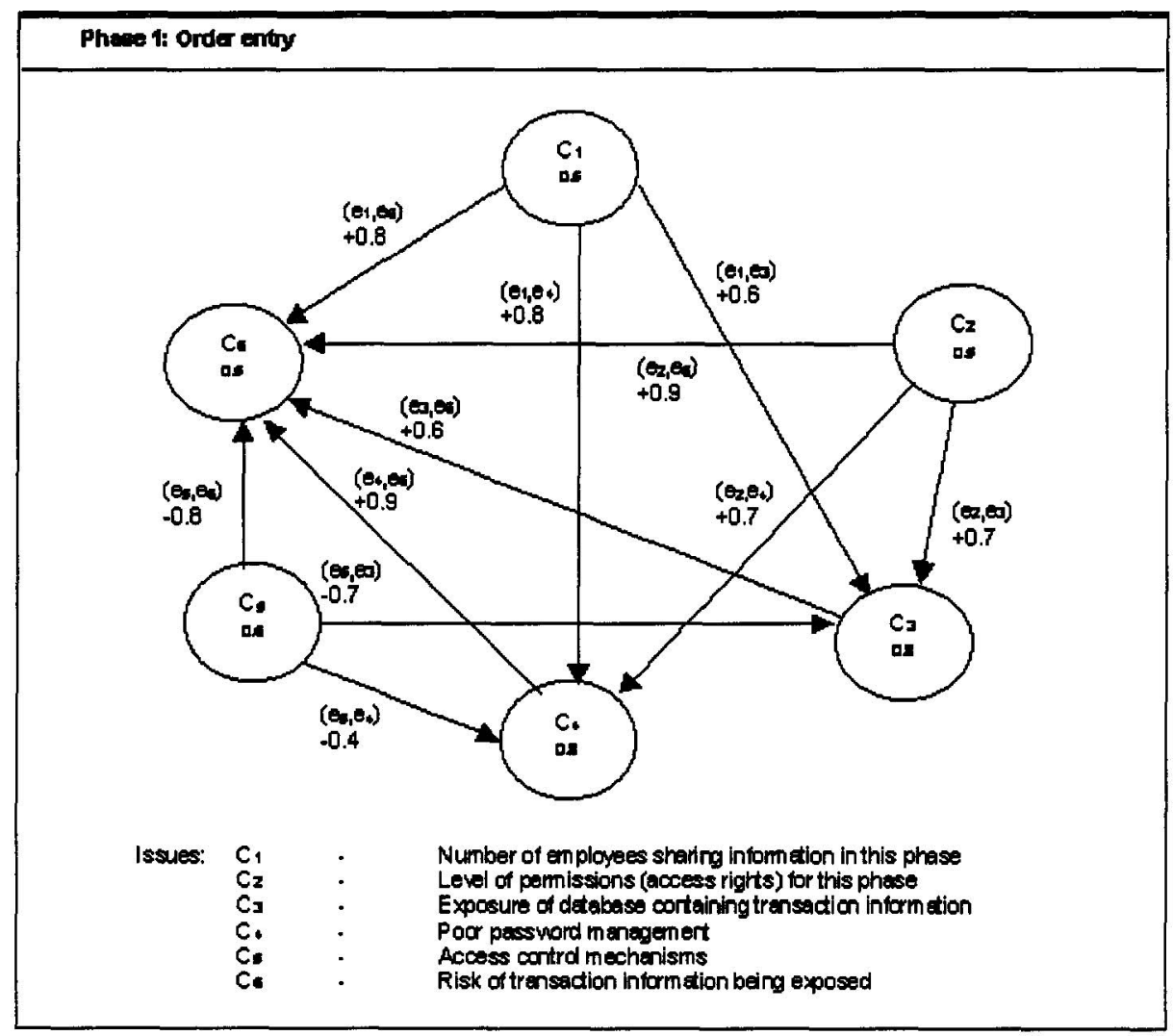

Figure 4. FCM representing the relationships between the security related issues that play a role in the order entry phase 
A number attached to the respective edge indicates the strength of a relationship. Consider the relationship between the risk of transaction information being exposed $\left(\mathrm{C}_{6}\right)$ and the number of employees sharing that transaction information $\left(\mathrm{C}_{1}\right)$. The plus 0.8 relationship between $\mathrm{C}_{1}$ and $\mathrm{C}_{6}$ implies, for instance, that if the number of employees sharing transaction information during the order entry phase were to increase, then the risk of transaction information being exposed during this phase would also increase by a degree of 0.8 , that is, by $80 \%$. If, by the same token, the number employees were to decrease, then the risk of transaction information being exposed would also decrease to the tune of $80 \%$. The strength of the relationship between the number of employees sharing transaction information and the risk of transaction information being exposed is, therefore, 0.8. The other plus relationships work in the same way.

The minus relationships, on the other hand, indicate the possibility of one issue increasing while decreasing another issue, and vice versa. In this way, the minus 0.7 relationship between $C_{5}$ and $C_{3}$ implies that if the strength of access control mechanisms implemented for the order entry phase were to increase, then the likelihood of database files containing transaction information being exposed would decrease to the tune of $70 \%$. The reverse is also true: if the strength of these access controls were to decrease, then the likelihood of database files containing transaction information being exposed would increase by a degree of $70 \%$. The strength of the relationship between the access control mechanisms and the exposure of database files containing transaction information is, therefore, 0.7. The other minus relationships works in the same way.

The final step in constructing the FCMs involves the specification of a trigger threshold for each issue. Such a trigger threshold (indicated by the number in the concept node that represents the issue) specifies the minimum strength to which the incoming relationship degrees must be aggregated in order to trigger the 'issue'.

Consider the following example: If the organisation is small, only a few employees, and the access rights allocated only include read and update, then it can be argued that poor password management would not be critical. This might be as a result of a culture of high trust (small company) and the policy of least privilege (read, update). However, if the organisation decides to increase the number of employees and allocate advanced access rights, such as append and delete, poor password management is critical and increase the risk significantly. The FCM implements this as follows: In order for $\mathrm{C}_{4}$, poor password management, to be triggered, the incoming relationships must 
be aggregated to a minimum of 0.8 , that is, $80 \%$. If, for example, the level of access privileges for obtaining access to the transaction were to increase $\left(\mathrm{C}_{2}\right)$ and an increasing number of employees were to share the transaction information $\left(\mathrm{C}_{1}\right)$, then the incoming relationships $\left(\mathrm{e}_{1}, \mathrm{e}_{4}\right)$ and $\left(\mathrm{e}_{2}, \mathrm{e}_{4}\right)$ need to aggregate to at least 0.8 in order for the "poor password management" $\left(\mathrm{C}_{4}\right)$ issue to be triggered. The thresholds of the other issues are determined in the same way. Like the strengths of the relationships between issues, the trigger thresholds are also determined in an intuitive manner.

\subsubsection{Construct edge matrices for the FCMs (Stage 4 task 4.3)}

A simple two-dimensional edge matrix can be used to represent the strengths of the relationships between issues. Following, an example of an edge matrix in figure 5 :

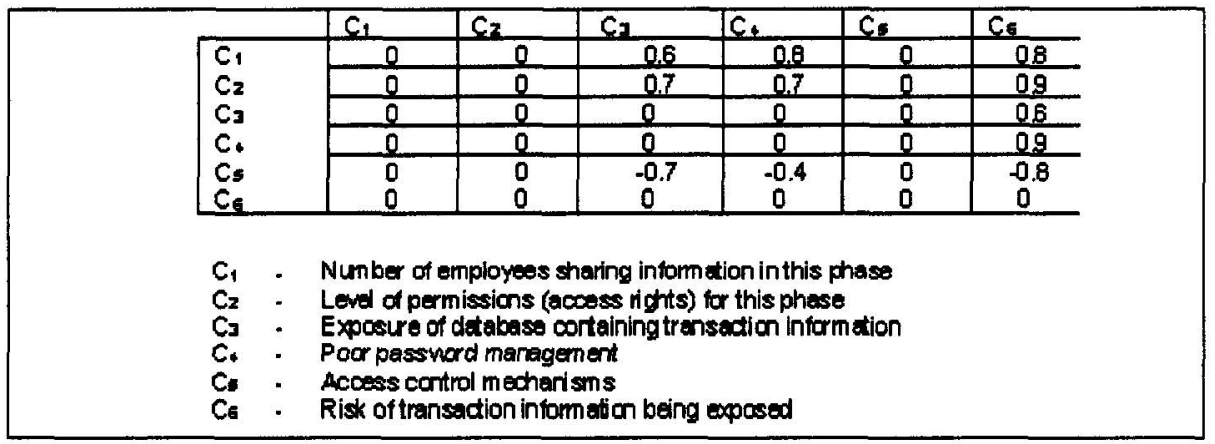

Figure 5. An edge matrix representing the strengths of the relationships between the various issues that take place during a critical phase (order entry)

The ith row lists the connection strength of the edges $\left(\mathrm{e}_{\mathrm{i}}, \mathrm{e}_{\mathrm{k}}\right)$ directed out from issue $\mathrm{C}_{\mathrm{i}}$. The first row in the matrix indicates, for example, that the strength of the relationship $\left(\mathrm{e}_{1}, \mathrm{e}_{3}\right)$ between $\mathrm{C}_{1}$ ("Number of employees sharing information in this phase") and $\mathrm{C}_{3}$ ("exposure of database files") is 0.6 , that the strength of $\left(\mathrm{e}_{1}, \mathrm{e}_{4}\right)$ between $\mathrm{C}_{1}$ and $\mathrm{C}_{4}$ ("Poor password management") is 0.8 and that the strength of $\left(\mathrm{e}_{1}, \mathrm{e}_{6}\right)$ between $\mathrm{C}_{1}$ and $\mathrm{C}_{6}$ is 0.8 .

Furthermore, $C_{i}$ causally increases $C_{k}$ if $\left(e_{i}, e_{k}\right)>0$, decreases $C_{k}$ if $\left(e_{i}, e_{k}\right)$ $<0$ and has no effect if $\left(\mathrm{e}_{\mathrm{i}}, \mathrm{e}_{\mathrm{k}}\right)=0$. Event $\mathrm{C}_{1}$ ("Number of employees sharing information in this phase"), for example, causally increases events $\mathrm{C}_{3}$ ("exposure of database files"), $\mathrm{C}_{4}$ ("Poor password management") and $\mathrm{C}_{6}$ ("risk of transaction information being 
exposed") to varying degrees, because $\left(\mathrm{e}_{1}, \mathrm{e}_{3}\right),\left(\mathrm{e}_{1}, \mathrm{e}_{4}\right)$ and $\left(\mathrm{e}_{1}, \mathrm{e}_{6}\right)$ are allgreater than 0 .

\subsubsection{Construct "What-if scenarios" (Stage 4 task 4.3)}

The edge matrix of the FCM can be used to explore various "What-if" scenarios in order to determine a way in which either to decrease such risk value or to explore whether or not a certain scenario would increase the risk value. What would happen if, for instance, poor password management becomes a problem? "What-if" scenarios such as these need to be constructed for this purpose.

Supposing that the IT risk value for a certain phase was calculated at 450 (on a scale of 0 to 1000 ). Each issue in an FCM triggers one or more other issues on (1) or off $(0)$. In order, for example, to model the "What-if" scenario, namely what would happen if, for instance, poor password management becomes a problem, event $\mathrm{C}_{4}$ ("Poor password management") needs to be turned on, that is, to be set equal to 1. All other events remain at 0 (remain unchanged).

This input state can be represented by the state vector $\left[\begin{array}{llllll}0 & 0 & 0 & 1 & 0 & 0\end{array}\right]$, in other words, each issue (node) in the FCM is represented by either a zero or a one in the state vector, depending on whether it be turned on or off. In our "What if" scenario, therefore, only the fourth element (representing $\mathrm{C}_{4}$ ) in the state vector has a value of 1. FCM input states such as these fire all the relationships in the FCM to some degree. This process will show how, in a fuzzy dynamic system, causal events (issues) affect each other to some degree as time goes by.

In order to model the effect of the input state $\mathrm{I}_{0}=\left[\begin{array}{llllll}0 & 0 & 0 & 1 & 0 & 0\end{array}\right]$ ("Poor password management") on the FCM for the order entry phase along the order-entry-and-delivering-of-goods transaction information route, the following technique is used to determine the new state (on or off) for each event Ci each time $\left(t_{n+1}\right)$ an input state fires the FCM.

$$
\mathrm{C}_{\mathrm{i}}\left(\mathrm{t}_{\mathrm{n}+1}\right)=\mathrm{S}\left(\sum_{\mathrm{K}=1}^{\mathrm{N}} \mathrm{e}_{\mathrm{ki}}\left(\mathrm{t}_{\mathrm{n}}\right) \mathrm{C}_{\mathrm{k}}\left(\mathrm{t}_{\mathrm{n}}\right)\right)
$$

This technique involves a matrix vector multiplication to transform the weighted input to each event (issue) $C_{i}$. In the above equation, $\mathrm{S}(\mathrm{x})$ is a bounded signal function, indicating whether $\mathrm{C}_{\mathrm{i}}$ be turned off (0) or on (1) [6].

The above equation is applied to the FCM with initial input state $\left[\begin{array}{llll}0 & 0 & 0 & 1\end{array}\right.$ 0 0] (that is, $\mathrm{C}_{4}$, "Poor password management", is turned on) as follows: 
$\mathrm{I}_{0}=\left[\begin{array}{llllll}0 & 0 & 0 & 1 & 0 & 0\end{array}\right]$, then

$\mathrm{I}_{0} \mathrm{E}_{\mathrm{c}}=\left[\sum_{\mathrm{k}=1}^{6} \mathrm{I}_{0 \mathrm{k}} \mathrm{e}_{\mathrm{k} 1}, \sum_{\mathrm{k}=1}^{6} \mathrm{I}_{0 \mathrm{k}} \mathrm{e}_{\mathrm{k} 2}, \sum_{\mathrm{k}=1}^{6} \mathrm{I}_{0 \mathrm{k}} \mathrm{e}_{\mathrm{k} 3}, \sum_{\mathrm{k}=1}^{6} \mathrm{I}_{0 \mathrm{k}} \mathrm{e}_{\mathrm{k} 4}, \sum_{\mathrm{k}=1}^{6} \mathrm{I}_{0 \mathrm{k}} \mathrm{e}_{\mathrm{k} 5}, \sum_{\mathrm{k}=1}^{6} \mathrm{I}_{0 \mathrm{k}} \mathrm{e}_{\mathrm{k} 6}\right]$,

where $I_{0 k}$ refers to the $k^{\text {th }}$ element in the state vector $I_{0}=\left[\begin{array}{llllll}0 & 0 & 0 & 1 & 0 & 0\end{array}\right]$ $\mathrm{e}_{\mathrm{k} 1}$ refers to the entry in the $\mathrm{k}^{\text {th }}$ row in the first column of the edge matrix $\mathrm{E}$

$\mathrm{e}_{\mathrm{k} 2}$ refers to the entry in the $\mathrm{k}^{\text {th }}$ row in the second column of the edge matrix E, and so forth.

$$
\begin{aligned}
& =[0 * 0+0 * 0+0 * 0+1 * 0+0 * 0+0 * 0, \\
& 0 * 0+0 * 0+0 * 0+1 * 0+0 * 0+0 * 0 \text {, } \\
& 0 * 0.6+0 * 0.7+0 * 0+1 * 0+0 *-0.7+0 * 0 \\
& 0 * 0.8+0 * 0.7+0 * 0+1 * 0+0 *-0.4+0 * 0 \\
& 0 * 0+0 * 0+0 * 0+1 * 0+0 * 0+0 * 0 \\
& 0 * 0.8+0 * 0.9+0 * 0.6+1 * 0.9+0 *-0.8+0 * 0 \text { ] } \\
& =\left[\begin{array}{llllll}
0 & 0 & 0 & 0 & 0 & 0.9
\end{array}\right] \stackrel{0.5}{\longrightarrow} \quad \mathrm{I}_{1}=\left[\begin{array}{llllll}
0 & 0 & 0 & 1 & 0 & 1
\end{array}\right]
\end{aligned}
$$

The arrow represents a threshold operation, with 0.5 the assumed threshold value. In other words, all entries in the state vector $\mathrm{I}_{0} \mathrm{Ec}$ with values higher than or equal to 0.5 are turned on. In addition, $\mathrm{C}_{4}$ is kept on, since we want to model the effect of a sustained threat of "Poor password management" being exposed during the order entry phase.

The following conclusion can, therefore, be made: when $\mathrm{I}_{0}$ fires the FCM (that is, when $\mathrm{I}_{0}$ occurs), then event $\mathrm{C}_{6}$ ("the risk of transaction information being exposed") is turned on. The next input state firing the FCM will, therefore, be $\mathrm{I}_{1}=\left[\begin{array}{llllll}0 & 0 & 0 & 1 & 0 & 1\end{array}\right]$.

The equation formulated earlier is applied to the FCM with input state $\mathrm{I}_{1}$ in the same way:

$$
\begin{aligned}
& I_{1} E_{c}=\left[\sum_{k=1}^{6} I_{1 k} e_{k 1}, \sum_{k=1}^{6} I_{1 k} e_{k 2}, \sum_{k=1}^{6} I_{1 k} e_{k 3}, \sum_{k=1}^{6} I_{1 k} e_{k 4}, \sum_{k=1}^{6} I_{1 k} e_{k s}, \sum_{k=1}^{6} I_{1 k} e_{k 6}\right] \\
& =\left[\begin{array}{llllll}
0 & 0 & 0 & 0 & 0 & 0.9
\end{array}\right] \stackrel{0.5}{\longrightarrow} \quad \mathrm{I}_{2}=\left[\begin{array}{lllll}
0 & 0 & 0 & 10 & 1
\end{array}\right]=\mathrm{I}_{1}
\end{aligned}
$$

This results in $\mathrm{C}_{6}$ remaining on. The next input state $\mathrm{I}_{2}=\left[\begin{array}{llllll}0 & 0 & 0 & 1 & 0 & 1\end{array}\right]$ is, therefore, equal to the previous input state $\mathrm{I}_{1}$. For this reason, the FCM converges to a fixed point $\mathrm{I}_{2}$ that turns on $\mathrm{C}_{6}$ ("the risk of transaction information being exposed"). This means that "Poor password management" in the order entry phase would increase the risk of transaction information being exposed $\left(\mathrm{C}_{6}\right)$. 
The reader is referred to [6] for more information on this technique.

The foregoing example illustrates how an edge matrix constructed from an FCM can be used to explore "What-if" scenarios.

\subsection{Identify the security services and controls (Stage 4 task 4.4)}

Modelling "What-if" scenarios by making use of FCMs can, naturally, greatly facilitate decisions on the implementation of security controls for a specific phase along a transaction information route.

Consider the previous example, which hinges upon the exploration of a "What-if" scenario. The outcome of the scenario was that poor password management would indeed increase the risk of transaction information being exposed. The confidentiality of the transaction information would, therefore, be under threat. Furthermore, an unauthorised person gaining access to transaction information could also alter such information, thereby compromising its integrity.

In the foregoing example, confidentiality and integrity have been identified as the security services being under threat as a result of poor password management. It is essential in this case, therefore, to implement security controls in order to protect the confidentiality and integrity of the transaction information during the phase under consideration. For example, security controls such as improved password management and/or biometrics could be implemented in order to secure the transaction information.

\subsection{Compile a report to this effect and obtain management approval (Stage 4 task 4.5)}

Before the necessary security controls could be implemented, however, a report would have to be compiled in order to verify the need for such controls. The report must then be submitted to management in order to obtain its approval of the proposed security controls.

\subsection{Devise a project plan (stage 4 task 4.6)}

Only after management has approved the said report could a project plan be devised. 


\section{CONCLUSION}

This paper has been devoted to the presentation of a risk-management methodology specifically developed for assessing and analysing risks incurred by the business transactions of an organisation. The aim of the methodology is to enhance risk management by following a cognitive fuzzy approach to the assessment and analysis of risks. The advantage of using this approach is that the intuitive nature of human observation, which forms the basis of any risk assessment, and the vagueness regarding the decisionmaking process with respect to securing transaction information, are both taken into account when assessing and analysing IT risks.

The risk-analysis (fourth) stage of the methodology has been discussed in detail in this paper. The principal aim of this stage was to help manage risks by facilitating the decision-making process. This was achieved by first identifying the critical phases (that is, the high-risk phases) along each transaction information route by using the risk values calculated for each phase during the risk-assessment stage. Having identified these critical phases, the critical transaction information routes (high-risk transaction information routes) could be identified by aggregating the risk values of all phases comprising the specific transaction information route. In this way, the high-risk areas in an organisation can be pinpointed.

Furthermore, the cognitive fuzzy-modelling approach followed by the proposed methodology also enables the investigation of these critical areas with a view to enhancing the level of information security. This is achieved by making use of an FCM and by constructing various "What-if" scenarios to determine which of them might lead to the increase/decrease of a risk incidence. In this way, the decision-making process with respect to enhancing the overall information security is facilitated.

We aim our further research at developing a prototype to illustrate the functioning of the risk analysis stage and to prove that the model is not merely a theoretical concept, but that it can indeed be implemented successfully. 


\section{LIST OF SOURCES CONSULTED}

[1] LABUSCHAGNE, L. 1992. "Inligtingsekerheid, met spesifieke verwysing na risikoontleding." Rand Afrikaans University. Johannesburg, South Africa (dissertation (MCom) - RAU).

[2] PFLEEGER, C.P. 1997. Security in computing. United States of America: Prentice-Hall International Inc. $574 \mathrm{p}$.

[3] BADENHORST, K.P \& ELOFF, J.H.P. 1989. Framework of a methodology for the life cycle of computer security in an institution. Computers \& Security. 8: 433-442.

[4]ELOFF, J.H.P. \& SMITH E. 2000. Cognitive fuzzy modeling for enhanced risk assessment in a health care institution. IEEE Intelligent systems \& their applications. $15(2): 69-75$.

[5] COX, E.D. 1994. The fuzzy systems handbook: A practitioner's guide to building, using and maintaining fuzzy systems. Boston: Academic Press. $515 \mathrm{p}$.

[6] KOSKO, B. 1997. Fuzzy engineering. New Jersey: Prentice-Hall. 549 p.

[7] KOSKO, B. 1986. Fuzzy cognitive maps. International Journal of Man-machine Studies. 24: 65-75.

[8] COX, E.D. 1995. Fuzzy logic for business and industry. Massachusetts: Charles River Media Inc. $601 \mathrm{p}$. 